\title{
Altered Plasma Levels of Glial Cell Line-Derived Neurotrophic Factor in Patients with Internet Gaming Disorder: A Case-Control, Pilot Study
}

\author{
Jo-Eun Jeong', Soo-Hyun Paik' ${ }^{2}$ Mi Ran $\mathrm{Choi}^{3}$, Hyun $\mathrm{Cho}^{3,4}$, \\ Jung-Seok Choi ${ }^{5,6}$, Sam-Wook Choi ${ }^{7}$, and Dai-Jin Kim ${ }^{8} \bowtie$ \\ 1'Department of Psychiatry, Daejeon St. Mary's Hospital, College of Medicine, The Catholic University of Korea, Daejeon, Republic of Korea \\ ${ }^{2}$ Department of Psychiatry, Keyo Hospital, Keyo Medical Foundation, Uiwang, Republic of Korea \\ ${ }^{3}$ Addiction Laboratory, Department of Psychiatry, College of Medicine, The Catholic of University of Korea, Seoul, Republic of Korea \\ ${ }^{4}$ Department of Psychology, Korea University, Seoul, Republic of Korea \\ ${ }^{5}$ Department of Psychiatry, SMU-SNU Boramae Medical Center, Seoul, Republic of Korea \\ ${ }^{6}$ Department of Psychiatry, Seoul National University College of Medicine, Seoul, Republic of Korea \\ ${ }^{7}$ Department of Psychiatry, True Mind Mental Health Clinic, Seoul, Republic of Korea \\ ${ }^{8}$ Department of Psychiatry, Seoul St. Mary's Hospital, College of Medicine, The Catholic University of Korea, Seoul, Republic of Korea
}

Glial cell line-derived neurotrophic factor (GDNF) has been reported to be involved in negatively regulating the effects of addictive disorders. The objective of this study was to investigate alterations in the levels of GDNF in patients with Internet gaming disorder (IGD) and to assess the relationship between GDNF levels and the severity of IGD indices. Nineteen male patients with IGD and 19 sexmatched control subjects were evaluated for alteration of plasma GDNF levels and for relationship between GDNF levels and clinical characteristics of Internet gaming, including the Young's Internet Addiction Test (Y-IAT). The GDNF levels were found to be significantly low in patients with IGD $(103.2 \pm 62.0 \mathrm{pg} / \mathrm{mL})$ compared with the levels of controls $(245.2 \pm 101.6 \mathrm{pg} / \mathrm{mL}, \mathrm{p}<0.001)$. GDNF levels were negatively correlated with Y-IAT scores (Spearman's $r h o=-0.645, \mathrm{p}=<0.001$ ) and this negative correlation remained even after controlling for multiple variables $(\mathrm{r}=-0.370, \mathrm{p}=0.048)$. These findings support the assumed role of GDNF in the regulation of IGD.

Psychiatry Investig 2019;16(6):469-474

Key Words Glial cell line-derived neurotrophic factor, Behavior, Addictive, Internet, Game, Recreational.

\section{INTRODUCTION}

Glial cell line-derived neurotrophic factor (GDNF) is neuropeptide and it is essential for the maintenance of dopaminergic neurons ${ }^{1}$ and has been shown to enhance re-growth of adult dopamine neurons following neural insult. ${ }^{2}$

Furthermore, several preclinical studies indicate that GDNF plays an important role in the behavioral effects of abused drugs $^{3}$ and neuroadaptation induced by repeated exposure to drugs, including cocaine, ${ }^{4,5}$ methamphetamine, ${ }^{6,7}$ morphine, ${ }^{8}$

Received: November 26, 2018 Revised: February 8, 2019 Accepted: April 2, 2019

$\triangle$ Correspondence: Dai-Jin Kim, MD, PhD

Department of Psychiatry, Seoul St. Mary's Hospital, College of Medicine, The Catholic University of Korea, 222 Banpo-daero, Seocho-gu, Seoul 06591, Republic of Korea

Tel: +82-2-2258-6933, Fax: +82-2-594-3870, E-mail: kdj922@chollian.net

(c) This is an Open Access article distributed under the terms of the Creative Commons Attribution Non-Commercial License (https://creativecommons.org/licenses/bync/4.0) which permits unrestricted non-commercial use, distribution, and reproduction in any medium, provided the original work is properly cited. and alcohol ${ }^{9-11}$ in the mesolimbic dopamine pathway. Intriguingly, most of the studies suggest that activation of the GDNF system results in the prevention of behavioral adaptation to drugs of abuse. ${ }^{3}$ Intra-ventral tegmental area (VTA) infusion of GDNF was effective in decreasing conditioned place preference (CPP) to cocaine ${ }^{3}$; GDNF heterozygote knockout mice, which express lower GDNF levels than their wild-type counterparts, show increased methamphetamine $e^{6}$ and morphine $\mathrm{CPP}^{8}$ In addition, previous studies have suggested that GDNF reduces ethanol consumption and relapse. ${ }^{9-11}$

Internet gaming disorder (IGD) is currently included in Section III of the $5^{\text {th }}$ edition of the Diagnostic and Statistical Manual of Mental Disorders (DSM-5) and the DSM-5 proposed that IGD is a pattern of excessive and prolonged Internet gaming that results in a cluster of cognitive and behavioral symptoms, including loss of control over gaming, tolerance, and withdrawal symptoms. ${ }^{12}$ These characteristics are traditionally associated and shared with substance-related addic- 
tions $^{12,13}$ and gambling disorder. ${ }^{14,15}$ Furthermore, from a neurobiological perspective, recent neuroimaging studies have shown that IGD may have an impact on the dopaminergic system. ${ }^{13}$ Dopaminergic neurons in the VTA are a critical element of the neural circuitry implicated in addictive behavior and the mesolimbic dopaminergic circuit has also been implicated in addiction. ${ }^{16}$ In studies using positron emission tomography scanning, ${ }^{17,18}$ increased release of dopamine to D2 receptors, especially in the ventral striatum, was suggested following a game play in a healthy male adult. Another study using single photon emission computed tomography ${ }^{19}$ suggests that the level of dopamine release in the ventral striatum during an Internet game is comparable to that induced by psychostimulant drugs. ${ }^{20,21}$

These findings suggest that GDNF, which plays a role in mesolimbic dopamine circuits, is associated with IGD. However, there are no clinical study results that show altered levels of GDNF in IGD. Therefore, the aims of the present study were to investigate alterations in the plasma levels of GDNF in IGD patients compared to that in healthy controls and to assess the relationship between GDNF levels and the severity of IGD indices.

\section{METHODS}

\section{Participants}

Nineteen male IGD patients were recruited and diagnosed according to the DSM- 5 criteria. The patients were still playing Internet games at the time of enrollment and had not previously received any treatment for IGD. IGD group subjects with past or current medical disorders, neurological disorders, or other psychiatric disorders including substance use disorders were excluded. The control group consisted of 19 healthy male subjects and was negative for medical, neurological, and psychiatric disorders and regular use of any medication.

\section{Measures and procedure}

Participants were assessed using the Alcohol Use Disorders Identification Test (AUDIT), ${ }^{22}$ Fagerström Test for Nicotine Dependence (FTND) ${ }^{23}$ Beck Depression Inventory (BDI)-II, ${ }^{24}$ Beck Anxiety Inventory (BAI)-II, ${ }^{25}$ and Barratt Impulsiveness Scale-11 (BIS-11). ${ }^{26}$ The characteristics of their Internet gaming were measured by the first period of Internet gaming, weekday/weekend average Internet gaming usage hours for the past year, elapsed time after the last game, and the Korean version of Young's Internet Addiction Test (Y-IAT) to assess the severity of IGD. The Y-IAT comprised 20 items with 5 Likert scales ranging from 1 (Not at all) to 5 (Always) with higher scores indicating a greater tendency to- ward addiction. ${ }^{27}$ Y-IAT scores of 20-39 are regarded as an average user, 40-69 as a possible addicted user, and more than 70 as an addicted user. ${ }^{27}$ In a previous study to explore the psychometric properties of the Y-IAT, six factors were identified; salience, excessive use, neglecting work, anticipation, lack of control, and neglecting social life. ${ }^{28}$ All subjects were also examined using the Korean Wechsler Adult Intelligence Scale (K-WAIS) to measure their intelligence quotient (IQ) and cognitive ability.

GDNF concentration was measured by enzyme-linked immunosorbent assay (ELISA) according to the manufacturer's instructions (Wuhan EIAab Science Co., Ltd., China). Further explanation on the measurement of plasma GDNF are provided in the Supplementary Materials (in the onlineonly Data Supplement).

This study was approved by the Institutional Review Board (IRB) of Seoul St. Mary's Hospital (IRB number: KC15EISI0103). All subjects were informed about the study and all provided informed consent.

\section{Statistical analyses}

Differences in sociodemographic, clinical variables, and plasma GDNF levels between the IGD and control groups were tested using the independent t-test, Mann-Whitney U test, or Fisher's exact test. The correlation between GDNF levels and clinical characteristics in all participants was examined using Spearman's rho and partial correlation that controlled for age, AUDIT, FTND, BDI-II, BAI-II and BIS11 scores, and total IQ. All statistical analyses were conducted using SPSS, version 24.0 (IBM Corp., Armonk, NY, USA).

\section{RESULTS}

The sociodemographic, clinical characteristics, and GDNF levels of the IGD patients and control subjects are listed in Table 1. In the IGD group, the average playing duration per weekday or weekend day was $2.5 \pm 2.0$ hours and $4.0 \pm 1.9$ hours, respectively. The Y-IAT score of IGD patients was $52.1 \pm 10.0$, which is regarded as possibly addicted. There was no difference in mean age, marital and employment status, smoking and alcohol drinking status, beginning of Internet gaming, weekday and weekend average usage hours of Internet gaming, elapsed time after the last game, and AUDIT, FTND, BDI-II, BAI-II, and K-WAIS scores between the two groups. However, the mean Y-IAT and BIS-11 scores were significantly higher in the IGD group (75.1 \pm 26.1 at BIS-11) than in the normal control group (38.8 \pm 5.1 and $54.9 \pm 17.0$, respectively). With regard to the six factors of Y-IAT, the scores were higher in the IGD group compared to normal controls except for the salience factor. The mean plasma 
GDNF levels were found to be significantly low in the patients with IGD $(103.2 \pm 62.0 \mathrm{pg} / \mathrm{mL})$ when compared with those of the healthy controls $(245.2 \pm 101.6 \mathrm{pg} / \mathrm{mL}, \mathrm{p}<0.001)$ (Table 1$)$.
GDNF plasma levels were negatively correlated with BIS11 scores (Spearman's rho $=-0.526, \mathrm{p}=0.001$ ) but not significantly correlated with age $(p=0.536)$ AUDIT $(p=0.084)$,

Table 1. Sociodemographics, clinical characteristics, and GDNF levels of subjects

\begin{tabular}{|c|c|c|c|}
\hline Variables & $\begin{array}{c}\text { IGD } \\
(\mathrm{N}=19, \text { male })\end{array}$ & $\begin{array}{c}\text { Controls } \\
(\mathrm{N}=19, \text { male })\end{array}$ & p-value \\
\hline Age, mean years (SD) & $31.2(8.0)$ & $31.3(4.2)$ & 0.817 \\
\hline Marital status, N (\%) & & & 0.495 \\
\hline Unmarried & $14(73.7)$ & $11(57.9)$ & \\
\hline Married & $5(26.3)$ & $8(42.1)$ & \\
\hline Employment status, N (\%) & & & 0.313 \\
\hline Yes & $10(52.6)$ & $14(73.7)$ & \\
\hline No & $9(47.4)$ & $5(26.3)$ & \\
\hline Smoking, N (\%) & & & 1.000 \\
\hline Non-smoker & $6(31.6)$ & $6(31.6)$ & \\
\hline Current smoker & $13(68.4)$ & $13(68.4)$ & \\
\hline Alcohol, N (\%) & & & 1.000 \\
\hline Non-drinker & $7(36.8)$ & $6(31.6)$ & \\
\hline Drinker & $12(63.2)$ & $13(68.4)$ & \\
\hline AUDIT, mean (SD) & $9.4(11.5)$ & $10.6(9.0)$ & 0.452 \\
\hline FTND, mean (SD) & $2.4(4.7)$ & $2.8(4.8)$ & 0.977 \\
\hline First period of Internet gaming, N (\%) & & & 0.831 \\
\hline Lower grade of elementary school & $1(5.3)$ & $0(0.0)$ & \\
\hline Upper grade of elementary school & $2(10.5)$ & $3(15.8)$ & \\
\hline Middle school & $6(31.6)$ & $5(26.3)$ & \\
\hline High school & $3(15.8)$ & $6(31.6)$ & \\
\hline $20 \mathrm{~s}$ & $5(26.3)$ & $4(21.0)$ & \\
\hline $30 \mathrm{~s}$ & $2(10.5)$ & $1(5.3)$ & \\
\hline Weekday average Internet game usage hours, mean hours/day (SD) & $2.5(2.0)$ & $1.9(1.1)$ & 0.181 \\
\hline Weekend average Internet game usage hours, mean hours/days (SD) & $4.0(1.9)$ & $3.3(1.7)$ & 0.271 \\
\hline Elapsed time after the last game, mean hours (SD) & $16.7(9.2)$ & $19.0(12.3)$ & 0.311 \\
\hline Y-IAT, mean (SD) & $52.1(10.0)$ & $38.8(5.1)$ & $<0.001^{*}$ \\
\hline Salience & $11.0(2.0)$ & $9.8(2.6)$ & 0.172 \\
\hline Excessive use & $15.1(3.3)$ & $11.1(1.3)$ & $<0.001^{*}$ \\
\hline Neglecting work & $7.9(2.8)$ & $5.0(1.6)$ & $<0.001^{*}$ \\
\hline Anticipation & $4.6(1.6)$ & $3.3(1.5)$ & $0.023^{*}$ \\
\hline Lack of control & $8.5(2.5)$ & $6.3(1.5)$ & $0.003^{*}$ \\
\hline Neglecting social life & $5.1(1.3)$ & $3.4(1.1)$ & $<0.001^{*}$ \\
\hline BDI-II, mean (SD) & $21.1(5.5)$ & $17.8(7.9)$ & 0.142 \\
\hline BAI-II, mean (SD) & $20.7(5.0)$ & $17.1(11.4)$ & 0.109 \\
\hline BIS-11, mean (SD) & $75.1(26.1)$ & $54.9(17.0)$ & $0.019^{*}$ \\
\hline GDNF, pg/mL (SD) & $103.2(62.0)$ & $245.2(101.6)$ & $<0.001^{*}$ \\
\hline K-WAIS, full scale IQ, mean (SD) & $104.9(17.0)$ & $108.4(11.6)$ & 0.460 \\
\hline
\end{tabular}

${ }^{*} \mathrm{p}<0.05$ in independent t-test, Mann-Whitney U test, or Fisher's exact test. IGD: Internet gaming disorder patients, SD: standard deviation, N: numbers, AUDIT: alcohol use disorders identification test, FTND: Fagerström test for nicotine dependence, Y-IAT: Young's Internet addiction test, BDI: Beck depression inventory, BAI: Beck anxiety inventory, BIS: Barratt Impulsiveness Scale, GDNF: glial cell line-derived neurotrophic factor, K-WAIS: Korean Wechsler Adult Intelligence Scale, IQ: Intelligence quotient 
FTND ( $\mathrm{p}=0.497)$, BDI-II $(\mathrm{p}=0.164)$ and BAI-II $(\mathrm{p}=0.138)$ scores, and total IQ ( $\mathrm{p}=0.884)$. Regarding gaming characteristics and IGD severity, GDNF levels were negatively correlated with Y-IAT scores (Spearman's rho $=-0.645, \mathrm{p}=<0.001$ ) and positively correlated with elapsed time after the last game (Spearman's rho $=0.420, \mathrm{p}=0.009$ ) but not significantly correlated with weekday $(\mathrm{p}=0.126)$ and weekend average Internet gaming usage hours ( $\mathrm{p}=0.074)$. After controlling age, AUDIT, FTND, BDI-II, BAI-II and BIS-11 scores, and total IQ, a negative correlation remained between plasma GDNF levels and Y-IAT scores $(\mathrm{r}=-0.370, \mathrm{p}=0.048)$ and a negatively correlated trend was observed between GDNF levels and Y-IAT salience sub-factor scores $(\mathrm{r}=-0.339, \mathrm{p}=0.055)$ (Figure 1).

\section{DISCUSSION}

In this study, we found significantly lower plasma GDNF levels among patients with IGD than in healthy controls. This finding is consistent with a previous study in which GDNF levels were lower in alcohol-dependent patients. ${ }^{29}$ In addition, we found a negative correlation between GDNF levels and IGD severity. Similar to the present results, a previous study with heavy alcohol drinkers (years of drinking: 8.85 \pm 7.38 , daily alcohol consumption: $193.27 \pm 58.59$ grams) reported that GDNF levels were negatively associated with tolerance. $^{29}$

We also found that salience showed a negative correlated trend with GDNF levels. Salience, specifically incentive salience, is a cognitive process that produces a bias of attentional processing toward reward-associated stimuli ${ }^{30-32}$ and

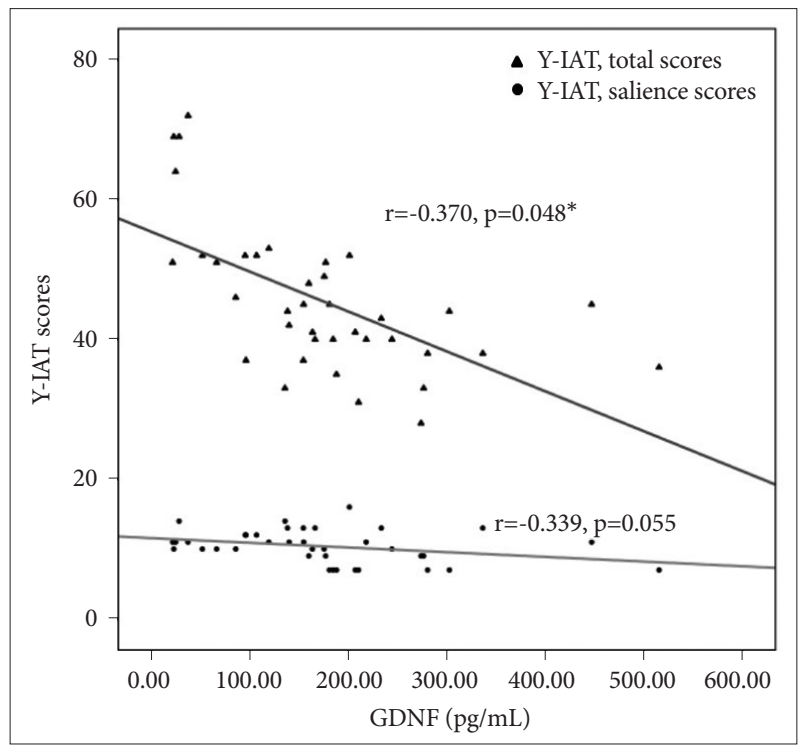

Figure 1. Partial correlation between plasma GDNF levels and $Y$ IAT total and salience scores. ${ }^{*} p<0.05$. GDNF: glial cell line-derived neurotrophic factor, Y-IAT: Young's Internet addiction test. regulated primarily by dopamine neurotransmission in the mesocorticolimbic pathway. ${ }^{32,33}$ GDNF is associated with the mesolimbic dopaminergic system; the main area of action of GDNF is the midbrain ${ }^{11,34,35}$ and the main site of GDNF in the midbrain is the striatum. ${ }^{36-38}$ Moreover, signaling proteins for GDNF, GFR $\alpha 1$ (GDNF family receptor $\alpha 1$ ) and Ret (Rearranged during transfection receptor), are highly expressed in midbrain dopamine neurons. ${ }^{39,40}$ Additionally, motivation to self-administer and amphetamine-seeking behavior related to incentive salience is enhanced and sensitivity to the rewarding activity is increased in GDNF heterozygote knockout mice. ${ }^{3,7}$

The mechanisms of action of GDNF associated with addiction remain unknown at present. However, several studies suggest that increased GDNF levels are associated with a reduction in the activity of tyrosine hydroxylase, the rate-limiting enzyme for dopamine synthesis, in the midbrain., ${ }^{3,41,42}$ GDNF VTA injections antagonized cocaine or morphine-induced induction of tyrosine hydroxylase, which its activation enhances dopamine release in terminal areas. ${ }^{3}$ These changes could result in a synaptic alteration, changing the responsiveness of the mesolimbic dopaminergic system and subsequently blunting the incentive and/or rewarding property, and the neuroadaptations associated with addiction.

The present study has the following limitations; first, our sample size was modest, and we investigated plasma levels of GDNF in only male patients. Previous animal studies have shown gender differences in the regulation of neurotrophic factors. ${ }^{43,44}$ Second, our sample did not include IGD patient with severe levels of severity such as patients who require hospitalization. Third, plasma GDNF levels were measured in peripheral blood rather than in the central nervous system although a prior study reported that reduced GDNF plasma levels may imply a decreased ability to repair neuronal injury. ${ }^{45}$

Despite these limitations, it is worth noting that this research is the first clinical study to investigate alterations in GDNF levels in IGD. The present study showed that GDNF levels are significantly lower in IGD patients compared to controls and GDNF levels have a negative correlation with IGD severity. The findings of this study support the assumed role of GDNF in the regulation of addiction including IGD as observed in preclinical studies. Our findings show the possibility of the GDNF pathway as a promising target for understanding and treatment of addictions including IGD.

\section{Supplementary Materials}

The online-only Data Supplement is available with this article at https://doi.org/10.30773/pi.2019.04.02.2.

\section{Acknowledgments}

This research was supported by the Brain Research Program through 
the National Research Foundation of Korea (NRF) funded by the Ministry of Science, ICT (NRF-2014M3C7A1062893).

\section{Conflicts of Interest}

The authors have no potential conflicts of interest to disclose.

\section{Author Contributions}

Conceptualization: Jo-Eun Jeong, Hyun Cho, Jung-Seok Choi, SamWook Choi, Dai-Jin Kim. Data curation: Jo-Eun Jeong, Hyun Cho. Formal analysis: Jo-Eun Jeong, Funding acquisition: Dai-Jin Kim. Investigation: Jo-Eun Jeong, Soo-Hyun Paik, Mi Ran Choi, Hyun Cho, Jung-Seok Choi, Sam-Wook Choi, Dai-Jin Kim. Methodology: Jo-Eun Jeong, Hyun Cho, Jung-Seok Choi, Sam-Wook Choi, Dai-Jin Kim. Project administration: Dai-Jin Kim. Resources: Jo-Eun Jeong, Hyun Cho. Software: Jo-Eun Jeong, Soo-Hyun Paik, Mi Ran Choi, Hyun Cho. Supervision: Jung-Seok Choi, Sam-Wook Choi, Dai-Jin Kim. Validation: Jung-Seok Choi, Sam-Wook Choi, Dai-Jin Kim. Visualization: Jo-Eun Jeong. Writing-original draft: Jo-Eun Jeong. Writing_-review \& editing: Jo-Eun Jeong.

\section{ORCID iDs}

Dai-Jin Kim

https://orcid.org/0000-0001-9408-5639

Jo-Eun Jeong

\section{REFERENCES}

1. Carnicella S, Ron D. GDNF--a potential target to treat addiction. Pharmacol Ther 2009;122:9-18.

2. Pascual A, Hidalgo-Figueroa M, Piruat JI, Pintado CO, Gómez-Díaz R, López-Barneo J. Absolute requirement of GDNF for adult catecholaminergic neuron survival. Nat Neurosci 2008;11:755-761.

3. Messer CJ, Eisch AJ, Carlezon WA Jr, Whisler K, Shen L, Wolf DH, et al. Role for GDNF in biochemical and behavioral adaptations to drugs of abuse. Neuron 2000;26:247-257.

4. Green-Sadan T, Kinor N, Roth-Deri I, Geffen-Aricha R, Schindler CJ, Yadid G. Transplantation of glial cell line-derived neurotrophic factorexpressing cells into the striatum and nucleus accumbens attenuates acquisition of cocaine self-administration in rats. Eur J Neurosci 2003; 18:2093-2098.

5. Green-Sadan T, Kuttner Y, Lublin-Tennenbaum T, Kinor N, Boguslavsky Y, Margel S, et al. Glial cell line-derived neurotrophic factorconjugated nanoparticles suppress acquisition of cocaine self-administration in rats. Exp Neurol 2005;194:97-105.

6. Niwa M, Nitta A, Yamada Y, Nakajima A, Saito K, Seishima M, et al. An inducer for glial cell line-derived neurotrophic factor and tumor necrosis factor-alpha protects against methamphetamine-induced rewarding effects and sensitization. Biol Psychiatry 2007;61:890-901.

7. Yan Y, Yamada K, Niwa M, Nagai T, Nitta A, Nabeshima T. Enduring vulnerability to reinstatement of methamphetamine-seeking behavior in glial-cell-line-derived neurotrophic factor mutant mice. FASEB J 2007;21:1994-2004.

8. Niwa M, Nitta A, Shen L, Noda Y, Nabeshima T. Involvement of glial cell line-derived neurotrophic factor in inhibitory effects of a hydrophobic dipeptide Leu-Ile on morphine-induced sensitization and rewarding effects. Behav Brain Res 2007;179:167-171.

9. Carnicella S, Kharazia V, Jeanblanc J, Janak PH, Ron D. GDNF is a fast-acting potent inhibitor of alcohol consumption and relapse. Proc Natl Acad Sci U S A 2008;105:8114-8119.

10. Carnicella S, Amamoto R, Ron D. Excessive alcohol consumption is blocked by glial cell line-derived neurotrophic factor. Alcohol 2009; 43:35-43.

11. He DY, McGough NN, Ravindranathan A, Jeanblanc J, Logrip ML, Phamluong K, et al. Glial cell line-derived neurotrophic factor mediates the desirable actions of the anti-addiction drug ibogaine against alcohol consumption. J Neurosci 2005;25:619-628.

12. The American Psychiatric Association. Diagnostic and Statistical Manual of Mental Disorders. Arlington, VA: The American Psychiatric Association; 2013.

13. Yau YH, Crowley MJ, Mayes LC, Potenza MN. Are Internet use and video-game-playing addictive behaviors? Biological, clinical and public health implications for youths and adults. Minerva Psichiatr 2012; 53:153-170.

14. Müller KW, Beutel ME, Egloff B, Wölfling K. Investigating risk factors for Internet gaming disorder: a comparison of patients with addictive gaming, pathological gamblers and healthy controls regarding the big five personality traits. Eur Addict Res 2014;20:129-136.

15. Kim H, Kim YK, Gwak AR, Lim JA, Lee JY, Jung HY, et al. Restingstate regional homogeneity as a biological marker for patients with Internet gaming disorder: A comparison with patients with alcohol use disorder and healthy controls. Prog Neuropsychopharmacol Biol Psychiatry 2015;60:104-111.

16. Pierce RC, Kumaresan V. The mesolimbic dopamine system: the final common pathway for the reinforcing effect of drugs of abuse? Neurosci Biobehav Rev 2006;30:215-238.

17. Kim SH, Baik SH, Park CS, Kim SJ, Choi SW, Kim SE. Reduced striatal dopamine D2 receptors in people with internet addiction. Neuroreport 2011;22:407-411.

18. Koepp MJ, Gunn RN, Lawrence AD, Cunningham VJ, Dagher A, Jones $\mathrm{T}$, et al. Evidence for striatal dopamine release during a video game. Nature 1998;393:266-268.

19. Weinstein AM. Computer and video game addiction-a comparison between game users and non-game users. Am J Drug Alcohol Abuse 2010;36:268-276.

20. Farde L, Nordström AL, Wiesel FA, Pauli S, Halldin C, Sedvall G. Positron emission tomographic analysis of central D1 and D2 dopamine receptor occupancy in patients treated with classical neuroleptics and clozapine. Relation to extrapyramidal side effects. Arch Gen Psychiatry 1992;49:538-544.

21. Volkow ND, Wang GJ, Fowler JS, Logan J, Schlyer D, Hitzemann R, et al. Imaging endogenous dopamine competition with [11C]raclopride in the human brain. Synapse 1994;16:255-262.

22. Kim CG, Kim JS, Jung JG, Kim SS, Yoon SJ, Suh HS. Reliability and validity of alcohol use disorder dentification test-Korean revised version for screening at-risk drinking and alcohol use disorders. Korean J Fam Med 2014;35:2-10.

23. Ahn HK, Lee HJ, Jung DS, Lee SY, Kim SW, Kang JH. The Reliability and validity of Korean version of questionnaire for nicotine dependence. J Korean Acad Fam Med 2002;23:999-1008.

24. Sung H, Kim J, Park Y, Bai D, Lee S, Ahn H. A study on the reliability and the validity of Korean version of the Beck Depression Inventory-II (BDI-II). J Korean Soc Biol Ther Psychiatry 2008;14:201-212.

25. Beck AT, Epstein N, Brown G, Steer RA. An inventory for measuring clinical anxiety: psychometric properties. J Consult Clin Psychol 1988; 56:893-897.

26. Chung Y, Lee C. A study of factor structures of the Barratt impulsiveness scale in Korean university students. Korean J Clin Psychol 1997; 16:117-129.

27. Young KS. Internet addiction: the emergence of a new clinical disorder. Cyberpsychol Behav 1998;1:237-244.

28. Widyanto L, McMurran M. The psychometric properties of the internet addiction test. Cyberpsychol Behav 2004;7:443-450.

29. Heberlein A, Muschler M, Wilhelm J, Frieling H, Lenz B, Gröschl M, et al. BDNF and GDNF serum levels in alcohol-dependent patients during withdrawal. Prog Neuropsychopharmacol Biol Psychiatry 2010;34:1060-1064.

30. Puglisi-Allegra S, Ventura R. Prefrontal/accumbal catecholamine system processes high motivational salience. Front Behav Neurosci 2012;6:31.

31. Schultz W. Neuronal reward and decision signals: from theories to data. Physiol Rev 2015;95:853-951.

32. Berridge KC. From prediction error to incentive salience: mesolimbic 
computation of reward motivation. Eur J Neurosci 2012;35:1124-1143.

33. Berridge KC, Kringelbach ML. Pleasure systems in the brain. Neuron 2015;86:646-664.

34. Golden JP, DeMaro JA, Osborne PA, Milbrandt J, Johnson EM Jr. Expression of neurturin, GDNF, and GDNF family-receptor mRNA in the developing and mature mouse. Exp Neurol 1999;158:504-528.

35. Semba J, Akanuma N, Wakuta M, Tanaka N, Suhara T. Alterations in the expressions of mRNA for GDNF and its receptors in the ventral midbrain of rats exposed to subchronic phencyclidine. Brain Res Mol Brain Res 2004;124:88-95.

36. Tomac A, Widenfalk J, Lin LF, Kohno T, Ebendal T, Hoffer BJ, et al. Retrograde axonal transport of glial cell line-derived neurotrophic factor in the adult nigrostriatal system suggests a trophic role in the adult. Proc Natl Acad Sci U S A 1995;92:8274-8278

37. Ai Y, Markesbery W, Zhang Z, Grondin R, Elseberry D, Gerhardt GA, et al. Intraputamenal infusion of GDNF in aged rhesus monkeys: distribution and dopaminergic effects. J Comp Neurol 2003;461:250-261.

38. Barroso-Chinea P, Cruz-Muros I, Aymerich MS, Rodríguez-Díaz M, Afonso-Oramas D, Lanciego JL, et al. Striatal expression of GDNF and differential vulnerability of midbrain dopaminergic cells. Eur J Neurosci $2005 ; 21: 1815-1827$

39. Treanor JJ, Goodman L, de Sauvage F, Stone DM, Poulsen KT, Beck
$\mathrm{CD}$, et al. Characterization of a multicomponent receptor for GDNF. Nature 1996;382:80-83.

40. Trupp M, Belluardo N, Funakoshi H, Ibáñez CF. Complementary and overlapping expression of glial cell line-derived neurotrophic factor (GDNF), c-ret proto-oncogene, and GDNF receptor-alpha indicates multiple mechanisms of trophic actions in the adult rat CNS. J Neurosci 1997;17:3554-3567.

41. Bourque MJ, Trudeau LE. GDNF enhances the synaptic efficacy of dopaminergic neurons in culture. Eur J Neurosci 2000;12:3172-3180.

42. Rosenblad C, Georgievska B, Kirik D. Long-term striatal overexpression of GDNF selectively downregulates tyrosine hydroxylase in the intact nigrostriatal dopamine system. Eur J Neurosci 2003;17:260-270.

43. Cirulli F, Francia N, Branchi I, Antonucci MT, Aloe L, Suomi SJ, et al. Changes in plasma levels of BDNF and NGF reveal a gender-selective vulnerability to early adversity in rhesus macaques. Psychoneuroendocrinology 2009;34:172-180.

44. Roeding RL, Perna MK, Cummins ED, Peterson DJ, Palmatier MI, Brown RW. Sex differences in adolescent methylphenidate sensitization: effects on glial cell-derived neurotrophic factor and brain-derived neurotrophic factor. Behav Brain Res 2014;273:139-143.

45. Choudhry MA, Chaudry IH. Alcohol, burn injury, and the intestine. J Emerg Trauma Shock 2008;1:81-87. 


\section{SUPPLEMENTARY MATERIAL}

\section{Measurement of plasma GDNF}

For the measurement of plasma GDNF levels, a total of $10 \mathrm{~mL}$ of blood was drawn from each participant. All blood samples were centrifuged and stored at $-80^{\circ} \mathrm{C}$ immediately after collection. The GDNF concentration was measured by enzyme-linked immunosorbent assay (ELISA) according to the manufacturer's instructions (Wuhan EIAab Science Co., Ltd., China). Each sample was examined in duplicate and the averages are reported. The assay range of the GDNF ELISA kit was $31.2-2,000 \mathrm{pg} / \mathrm{mL}$. 